\title{
How gender or culture affects first year Dutch and Swedish students' preferences for specialties and work-life issues
}

\author{
Margret van Tongeren-Alers ${ }^{1}$, Petra Verdonk ${ }^{2}$, Hans Bor ${ }^{1}$, Eva E. Johansson ${ }^{3}$, Katarina Hamberg 3 , \\ Antoine Lagro-Janssen ${ }^{1}$ \\ ${ }^{1}$ Radboud University Medical Center, Department of Primary and Community Care, Gender and Women's Health, the Netherlands \\ ${ }^{2}$ VU University Medical Center, Department of Medical Humanities, EMGO Institute for Health and Care Research, School of Medical \\ Sciences, the Netherlands \\ ${ }^{3}$ Umeå University, Department of Public Health and Clinical Medicine, Family Medicine, Umeå, Sweden
}

Correspondence: Margret van Tongeren-Alers, Radboud University Medical Center, Department of Primary and Community Care, Gender and Women's Health, the Netherlands. Email: Margret.vanTongeren-Alers@radboudumc.nl

\begin{abstract}
Objectives: We determine how gender or culture influence new medical students' specialty preferences and work-life issues and explore the relation between work-life issues and each specialty preference.

Methods: In a cross-sectional study, we surveyed first year Dutch and Swedish medical students $(\mathrm{N}=1173$, cohorts from 2006-2009) on their preferences for specialties, fulltime or part-time work, and agreement to eleven work-life issues. We tested differences by gender or culture using chi square and logistic regression.
\end{abstract}

Results: Over $93 \%$ of all students responded ( $\mathrm{N}=1095)$. Almost no male first year student preferred gynecology as a specialty. Dutch male students were more often interested in surgery, Dutch female students in paediatrics. In the Netherlands, male students in particular preferred full-time work. In Sweden gender did not influence working hour preferences. Women in both countries expected equality in career-opportunities and care-tasks more than men, and agreed more often that their career would influence their family life. Women with a preference for surgery most often emphasized equality in career opportunities and care tasks. In most preferred specialties female gender related to a lower degree to full-time work. A gender gap in preferred working hours was larger for Dutch students preferring surgery or paediatrics than for Swedish students. For most of the specialty preferences studied, Swedish students anticipated childcare by day cares and Dutch students' informal day care.

Conclusions: Early in training, medical students have gendered specialty preferences and work-life preferences which relate to each other. Gender differences are significantly more pronounced in the Netherlands than in Sweden.

Keywords: Gender, medical students, specialty preference, work-life balance, culture

\section{Introduction}

Despite the fact that female and male students receive the same education, female and male physicians are not proportionally distributed across specialties (horizontal segregation) or in medical leadership (vertical segregation). ${ }^{1-4}$ Internationally, women outnumber men as medical students. ${ }^{2,5-7}$ Therefore, imbalances or even shortages within specialties in the future physician work force may occur in the future. So far, a considerable amount of research on gender differences in medical careers has emphasized the "life-side" of the work-life balance of female physicians. More often than their male counterparts, attractive working hours stipulate the specialty choice of female physicians, especially those with young children, and they have lower career prospects and realize their first career preference later in their careers. ${ }^{8-13}$ Intrinsic differences in motivational factors between men and women in the medical profession 
have also been considered, with male physicians attaching more importance to technical skills and female physicians being more patient-centred. ${ }^{2,14}$ Some of these factors could explain gender differences in medical careers which persist to this date. On the other hand, female physicians have proved to be as ambitious and ready to sacrifice their time as men. ${ }^{2,15,16}$ Motivation for a specialty may be an independent variable influencing specialty choice as well which consequently, may influence preferences for the 'life-side' of work-life balance. ${ }^{17}$ Thus, focusing on the influence of the "work" side of physicians' work-life balance might yield new understandings of the relationship between specialty choice and work-life issues.

During doctors' socialization, a way of perceiving, thinking and acting is formed, which may influence possible choices later in life. ${ }^{18}$ Role-models are assumed to be of great importance in the differences between female- and male physicians' careers. ${ }^{10,19}$ Culture also seems to be of great importance, especially in women's work participation. Even in countries with comparable welfare regimes and demographic figures, such as an ageing workforce, differences have been found. Two Western-European countries that exemplify cultural differences in workforce participation of women are the Netherlands and Sweden. In the Netherlands, most men work full-time and most women work part-time and take care of their children at home, a so called two-third earner model. ${ }^{20}$ Dutch working women have a paid pregnancy leave of four months and parents have the right to half a year unpaid parental leave. Dutch day cares are expensive with a governmental subsidizing system that often changes. Besides, day care is perceived as inflexible and inferior to parents' care. In Sweden, where national policies aim for gender equality in work and care, most men and women work full-time. ${ }^{13}$ One third of the women in Sweden work part-time, especially women with young children. Working parents are both entitled to a parental leave with payment in level with sickness benefit during 480 days in total for both parents, which could be transferred to the parent that takes care of the child the most. Day care in Sweden is widely accepted, is flexible, and the costs are bearable for most parents.

The above mentioned differences in working cultures may influence the future choice of specialty for medical students. In Sweden, male and female medical students might have more equal expectations toward work-life issues than in the Netherlands, regardless of equality in medical education. Career considerations when commencing medical education might change in time. However, students' specialty preferences at entry may be prospective to their ultimate specialty choice. ${ }^{21}$

In this study, we investigate specialty preferences of Dutch and Swedish medical students early on in their education, and the relationship of these preferences to gender. In addition, we are interested in how students anticipate on working hours and work-life issues, and whether their expectations towards work-life issues are related to specialty preferences. The first objective of our study is to determine differences between first year female and male medical students' preferences in specialty choice and work-life issues. Secondly, we explore how female and male students vary in their preferences for work-life issues for each specialty preference that first-year medical students have. For both objectives we specify cultural differences between the Netherlands and Sweden.

\section{Methods}

\section{Data collection}

We conducted a cross-sectional study. We surveyed first year medical students $(\mathrm{N}=1173)$ on gender issues in medicine at Radboud University Nijmegen Medical Center (the Netherlands, $\mathrm{N}=657,68 \%$ female) after their very first lecture (collected in 2006 and in 2007) and at Umeå University (Sweden, N=516, 54\% female) during their first week (between autumn of 2006 and spring of 2009). Participation was voluntary. The survey was completed anonymously. At Umeå University the Ethical Committee approved this study. In the Netherlands, ethical approval was not required for this type of study, because it does not involve patients. With regards to the number of male and female students, these numbers are similar to other medical schools in each country. The large majority of students in both schools have a white ethnic background (Swedish and Dutch). This study was part of the Gender Challenges in Medical Education Project. ${ }^{6}$ In this study we focus on a cross-cultural comparison of specialty preferences and work-life issues among first year students.

\section{Measures}

The questionnaire was translated from Dutch to English to Swedish and back to validate the content, solving any uncertainty by discussion among the authors. First, we asked questions about students' demographics, including age, marital status and having children and about their parents' educational level and current working hours. Next, we asked students to choose between seven specialties (internal medicine, psychiatry, neurology, paediatrics, surgery, gynecology and family medicine) or the options 'other, namely...' or 'I don't know'. The number of working hours students preferred in the future was categorized as full-time or part-time preference, no paid work or 'I don't know'. Finally, we assessed eleven issues on work-life balance, six on career issues and five on care tasks (answering categories varied from $1=$ totally disagree to $5=$ totally agree). In Table 1, these questions are included.

\section{Procedure}

When given more than one answer to specialty preferences, we categorized the preference as 'I don't know'. Approximately $2 \%$ of all medical students had no preference for working hours in which no gender differences were appar- 
ent. Next, we created a dichotomous variable for further analysis of full-time or part-time preference. A part-time worker was defined as an "employed person whose normal hours of work are less than those of a comparable full-time worker". ${ }^{22}$ In both countries, a doctor's full-time working week is over 40 hours. We defined part-time work as less than 36 hours.

Furthermore we made a dichotomous variable of the answers to each work-life issue in order to achieve a clear comparison between agreeing and not agreeing. We categorized each work-life issue variable into 'disagree' (including 'totally disagree', 'disagree' and 'neutral') and 'agree' (including 'agree', 'totally agree').

We categorized the parents' educational level into higher education (higher secondary or vocational school or university), intermediate education (intermediate secondary or vocational school), and lower education (lower secondary or vocational school or primary school).

\section{Data analysis}

In our analysis we focused on the role of gender (female, male) and working culture (The Netherlands, Sweden). With a Chi-square test, we compared students' demographics, specialty preference, full-time or part-time preference and agreement to work-life issues. Unpaired ttests were used to explore gender differences in age. For each specialty preference, including the undecided group, we used a logistic model to assess the relation between the outcome full-time work or agreement with particular worklife issues and the independent variables gender and working culture. We looked for a moderating effect of working culture on the relation between gender and the outcome variables by including an interaction effect to the model. If the effect was significant then an interaction term between gender and working culture was included to the model. As no Dutch male students and only one Swedish male student chose gynecology as a specialty, we analyzed differences between female students in both countries. Data were analyzed with SPSS 20.0 for windows.

\section{Results}

\section{Demographics}

In the Netherlands 616 of the 657 students responded (response rate $94 \%, 69.5 \%$ female) and in Sweden 479 of the 516 (response rate 93\%, 54\% female). Dutch students were on average 19 years old, none had children and $25 \%$ were in a relationship. Swedish students were older, with a mean age of 23 years. Half of the Swedish students were in a relationship and $4 \%$ had children. In both countries, most students had highly educated parents. Swedish mothers had the highest level of education and Dutch mothers the lowest level. Most fathers worked full-time. In Sweden, two thirds of the mothers worked full-time. In the Netherlands, two thirds of the mothers worked part-time and one fifth had no paid job.

\section{Specialty preferences}

Comparing female and male students revealed that almost no male student preferred gynecology (Table 1). Female and male students were equally distributed over the forty percent of the students with no specialty preference yet. Female and male students were also equally interested in family medicine.

In comparison to Swedish students where no specific gender differences in specialty preferences were found, Dutch male students highly stipulated surgery as their favourite specialty, whereas Dutch female students most often were interested in paediatrics.

\section{Preferences in work-life issues}

Concerning career and care issues female students in both countries attached more importance to equality in career opportunities and the impact that their career would have on family life than male students. Besides, female students anticipated equality in household chores and childcare by day cares more often than male students.

Comparing Dutch and Swedish students gender differences in working hour preference were highly present in the Netherlands and were not significant in Sweden. Dutch male students preferred full-time work and Dutch female students were more interested in part-time work. Dutch female students were less interested in full-time work than Swedish female students and Dutch male students were less interested in part-time work than Swedish male students were. Swedish students expected to a higher degree that there will be equality between partners in career opportunities. Concerning the care aspect of work-life issues, Swedish students attached more importance to an equal division of childcare between partners and anticipated on childcare organized by day care centres. Dutch students anticipated outsourcing household chores and indicated a preference for informal day care for children.

\section{Work-life issues related to specific specialty}

Comparing female and male students for those with a preference for paediatrics, internal medicine, family medicine, surgery, and for those who were undecided, female students were far less interested in full-time work than male students (Table 2). When preferring neurology or surgery as a specialty, women expected equal career opportunities far more often than male students. For family medicine or in the undecided group this relationship was also significantly present in the same direction. Female students preferring internal medicine, paediatrics, family medicine, surgery or being undecided, expected significantly more impact of their career on their family life than male students. 
Table 1. Gender and cultural differences in specialties, working hours and work-life issues $(\mathrm{N}=1095)$

\begin{tabular}{|c|c|c|c|c|c|c|}
\hline \multirow[b]{2}{*}{ Variables } & \multicolumn{3}{|c|}{ The Netherlands $(\mathrm{N}=616)$} & \multicolumn{3}{|c|}{ Sweden $(\mathrm{N}=479)$} \\
\hline & $\begin{array}{c}\text { Female } \\
(\mathrm{N}=428) \\
\mathrm{n}(\%)\end{array}$ & $\begin{array}{c}\text { Male } \\
(\mathrm{N}=188) \\
\mathrm{n}(\%)\end{array}$ & $\mathrm{p}$ & $\begin{array}{c}\text { Female } \\
(\mathrm{N}=259) \\
\mathrm{n}(\%)\end{array}$ & $\begin{array}{c}\text { Male } \\
(\mathrm{N}=220) \\
\mathrm{n}(\%)\end{array}$ & $\mathrm{p}$ \\
\hline \multicolumn{7}{|l|}{ Specialty preference } \\
\hline Internal medicine & $25(5.8)$ & $12(6.4)$ & 0.794 & $6(2.3)$ & $12(5.4)$ & 0.074 \\
\hline Psychiatry & $14(3.3)$ & $9(4.8)$ & 0.361 & $8(3.1)$ & $9(4.1)$ & 0.561 \\
\hline Neurology & $15(3.5)$ & $9(4.8)$ & 0.449 & $13(5)$ & $5(2.3)$ & 0.113 \\
\hline Paediatrics & $82(19.2)$ & $14(7.4)$ & $0.000^{*}$ & $31(12)$ & $22(10)$ & 0.483 \\
\hline Surgery & $42(9.8)$ & $48(25.5)$ & $0.000^{*}$ & $39(15.1)$ & $43(19.5)$ & 0.202 \\
\hline Gynecology & $25(5.8)$ & 0 & $0.001^{*}$ & $16(6.2)$ & $1(0.5)$ & $0.001^{*}$ \\
\hline Family medicine & $35(8.2)$ & $14(7.4)$ & 0.758 & $30(11.6)$ & $22(10)$ & 0.567 \\
\hline Other & $14(3.3)$ & $9(4.8)$ & 0.361 & $19(7.3)$ & $16(7.2)$ & 0.968 \\
\hline I don't know & $176(41.1)$ & $73(38.8)$ & 0.594 & $97(37.5)$ & $91(41.2)$ & 0.405 \\
\hline \multicolumn{7}{|l|}{ Working hours preference } \\
\hline Full-time & $212(50.6)$ & $153(83.2)$ & $0.000^{*}$ & $169(68.1)$ & $160(73.4)$ & 0.215 \\
\hline Part-time & $207(49.4)$ & $31(16.8)$ & & 79 (31.9) & $58(26.6)$ & \\
\hline \multicolumn{7}{|l|}{ Work-life issues } \\
\hline $\begin{array}{l}\text { You will have the same opportunities } \\
\text { concerning career and professional } \\
\text { satisfaction as your partner? }\end{array}$ & $314(73.7)$ & $104(55.3)$ & $0.000^{*}$ & $223(86.4)$ & $169(76.8)$ & $0.006^{*}$ \\
\hline $\begin{array}{l}\text { Your partner will be less ambitious concern- } \\
\text { ing a professional life than yourself? }\end{array}$ & $50(11.7)$ & $22(11.8)$ & 0.992 & $43(16.7)$ & $34(15.5)$ & 0.719 \\
\hline $\begin{array}{l}\text { Your job and career goals affect your } \\
\text { choices of having a family? }\end{array}$ & $320(74.8)$ & $121(64.4)$ & $0.008^{*}$ & $188(73.4)$ & $131(59.5)$ & $0.001^{*}$ \\
\hline $\begin{array}{l}\text { Having a family affects your job and career } \\
\text { aspirations? }\end{array}$ & $315(73.6)$ & $133(70.7)$ & 0.464 & $163(63.4)$ & $147(62.2)$ & 0.439 \\
\hline $\begin{array}{l}\text { Your partner's job and career goals affect } \\
\text { your choices to having a family? }\end{array}$ & $242(56.8)$ & $117(62.2)$ & 0.209 & $137(53.5)$ & $133(60.6)$ & 0.128 \\
\hline $\begin{array}{l}\text { Having a family affects your partner's job } \\
\text { and career aspirations? }\end{array}$ & $247(57.7)$ & $114(60.6)$ & 0.497 & $136(53.1)$ & $116(52.7)$ & 0.913 \\
\hline $\begin{array}{l}\text { You will equally share household chores } \\
\text { with your partner? }\end{array}$ & $322(75.2)$ & $89(47.3)$ & $0.000^{*}$ & $237(91.9)$ & $194(88.2)$ & 0.178 \\
\hline $\begin{array}{l}\text { The household chores will be mainly done } \\
\text { by someone else than you and your } \\
\text { partner? }\end{array}$ & $103(24.2)$ & 41 (21.9) & 0.545 & $18(7)$ & $20(9.1)$ & 0.394 \\
\hline $\begin{array}{l}\text { Both you and your partner will take equal } \\
\text { care of your children? }\end{array}$ & 325 (75.9) & $129(69.4)$ & 0.088 & $238(93)$ & 199 (90.5) & 0.319 \\
\hline $\begin{array}{l}\text { Besides you and your partner, care for your } \\
\text { children will be arranged by a day care } \\
\text { centre }\end{array}$ & $128(29.9)$ & 37 (19.7) & $0.008^{*}$ & $236(92.2)$ & $188(85.5)$ & $0.019^{*}$ \\
\hline $\begin{array}{l}\text { Besides you and your partner, care for your } \\
\text { children will be arranged by a nanny, } \\
\text { grandparents, or someone }\end{array}$ & $253(59.3)$ & $81(43.1)$ & $0.000^{*}$ & $42(16.4)$ & 35 (15.9) & 0.883 \\
\hline
\end{tabular}

In addition, women preferring family medicine anticipated that their career would be influenced by having a family, and also by the career of their partners. Amongst students preferring surgery, women underlined equality in childcare between partners more than men. Female students with a preference for paediatrics or who were undecided attached more importance to equality in household chores than males.

Comparing Dutch and Swedish students, we noticed that the gender gap in preferred working hours was larger for Dutch students preferring surgery or paediatrics than for Swedish students. In these specialties, Dutch female students preferred full-time work far less than Swedish female students, while Dutch male students anticipated full- time work more often than Swedish males. In the group with no preference yet, Dutch women less than Swedish women and Dutch men more than Swedish men, anticipated an impact of their partners' career on family life. Among students who preferred surgery or paediatrics, we found that Dutch students expected that their career might be influenced by family life more often than Swedish students. Compared to Dutch students, Swedish students preferring surgery or who were undecided agreed more on equality in career opportunities. In most specialty preferences, Swedish students attached more importance to equal household chores and childcare by day cares, whereas Dutch students anticipated outsourcing of household chores and informal day care for children for instance by grandparents. 
Tongeren-Alers et al. - How gender or culture affects students' preferences for specialties

Table 2. How gender or culture affects working hours and work-life issues in each specialty preference $(\mathrm{N}=1095)$

\begin{tabular}{|c|c|c|c|c|c|c|}
\hline \multirow{2}{*}{ Specialty } & \multirow{2}{*}{ Outcome $^{\dagger}$} & \multirow{2}{*}{ Predictor $^{* *}$} & \multirow{2}{*}{$\mathrm{p}$} & \multirow{2}{*}{ Odds Ratio } & \multicolumn{2}{|c|}{ 95\% C.I. for Odds Ratio } \\
\hline & & & & & Lower & Upper \\
\hline \multirow[t]{4}{*}{ Internal medicine } & Full-time work preference & Gender & $0.003^{*}$ & 0.04 & 0.00 & 0.34 \\
\hline & Career affects family & Culture & $0.040^{*}$ & 4.26 & 1.07 & 16.99 \\
\hline & Childcare by day care centre & Culture & $0.023^{*}$ & 0.20 & 0.05 & 0.80 \\
\hline & Childcare informal & Culture & $0.048^{*}$ & 3.73 & 1.01 & 13.75 \\
\hline \multirow[t]{7}{*}{ Psychiatry } & Career affects family & Gender & 0.236 & 0.30 & 0.04 & 2.20 \\
\hline & & Culture & 0.347 & 0.40 & 0.06 & 2.70 \\
\hline & & Gender ${ }^{*}$ Culture & $0.048^{*}$ & 15.28 & 1.02 & 228.93 \\
\hline & Equal household chores & Culture & $0.012^{*}$ & 0.05 & 0.00 & 0.52 \\
\hline & Household by someone else & Culture & $0.043^{*}$ & 9.72 & 1.08 & 87.50 \\
\hline & Childcare by day care centre & Culture & $0.001^{*}$ & 0.01 & 0.00 & 0.16 \\
\hline & Childcare informal & Gender & $0.047^{*}$ & 7.50 & 1.02 & 55.00 \\
\hline \multirow[t]{5}{*}{ Neurology } & Equal opportunities partners & Gender & $0.031^{*}$ & 4.74 & 1.15 & 19.57 \\
\hline & Family affects partners' career & Culture & $0.007^{*}$ & 7.04 & 1.72 & 28.76 \\
\hline & Equal household chores & Gender & $0.028^{*}$ & 4.90 & 1.18 & 20.26 \\
\hline & & Culture & $0.022^{*}$ & 0.12 & 0.02 & 0.74 \\
\hline & Childcare by day care centre & Culture & $0.001^{*}$ & 0.02 & 0.00 & 0.18 \\
\hline \multirow[t]{11}{*}{ Paediatrics } & Full-time work preference & Gender & $0.021^{*}$ & 3.97 & 1.23 & 12.84 \\
\hline & & Culture & $0.011^{*}$ & 17.33 & 1.90 & 158.00 \\
\hline & & Gender ${ }^{\star}$ Culture & $0.000^{*}$ & 0.01 & 0.00 & 0.12 \\
\hline & Career affects family & Gender & $0.028^{*}$ & 2.47 & 1.10 & 5.54 \\
\hline & Family affects career & Culture & $0.028^{*}$ & 2.38 & 1.10 & 5.13 \\
\hline & Family affects partners' career & Culture & $0.050^{*}$ & 2.08 & 1.00 & 4.33 \\
\hline & Equal household chores & Gender & $0.036^{*}$ & 3.13 & 1.08 & 9.08 \\
\hline & Household by someone else & Culture & $0.021^{*}$ & 5.92 & 1.30 & 26.94 \\
\hline & Equal care of children & Culture & $0.014^{*}$ & 0.14 & 0.03 & 0.67 \\
\hline & Childcare by day care centre & Culture & $0.000^{*}$ & 0.04 & 0.02 & 0.13 \\
\hline & Childcare informal & Culture & $0.000^{*}$ & 6.50 & 2.83 & 14.91 \\
\hline \multirow[t]{11}{*}{ Surgery } & Full-time work preference & Gender & 0.387 & 1.69 & 0.51 & 5.60 \\
\hline & & Culture & 0.284 & 1.85 & 0.60 & 5.72 \\
\hline & & Gender ${ }^{\star}$ Culture & $0.030^{*}$ & 0.17 & 0.03 & 0.84 \\
\hline & Equal opportunities partners & Gender & $0.002^{*}$ & 4.39 & 1.76 & 10.96 \\
\hline & & Culture & $0.010^{*}$ & 0.32 & 0.14 & 0.77 \\
\hline & Career affects family & Gender & $0.019^{*}$ & 2.56 & 1.17 & 5.62 \\
\hline & Family affects career & Culture & $0.048^{*}$ & 1.86 & 1.01 & 3.44 \\
\hline & Equal household chores & Culture & $0.000^{*}$ & 0.18 & 0.07 & 0.42 \\
\hline & Household by someone else & Culture & $0.001^{*}$ & 4.41 & 1.88 & 10.36 \\
\hline & Equal care of children & Gender & $0.008^{*}$ & 5.62 & 1.56 & 20.19 \\
\hline & Childcare by day care centre & Culture & $0.000^{*}$ & 0.04 & 0.02 & 0.08 \\
\hline Gynecology & Childcare informal & Culture (only female students) & $0.033^{*}$ & 4.50 & 1.13 & 17.99 \\
\hline \multirow[t]{8}{*}{ Family medicine } & Full-time work preference & Gender & $0.003^{*}$ & 0.24 & 0.10 & 0.62 \\
\hline & Equal opportunities partners & Gender & $0.024^{*}$ & 2.93 & 1.15 & 7.44 \\
\hline & Career affects family & Gender & $0.019^{*}$ & 2.81 & 1.18 & 6.68 \\
\hline & Family affects career & Gender & $0.002^{*}$ & 4.35 & 1.75 & 10.86 \\
\hline & Family affects partners' career & Gender & $0.023^{*}$ & 2.69 & 1.15 & 6.29 \\
\hline & Equal household chores & Culture & $0.009^{*}$ & 0.27 & 0.10 & 0.72 \\
\hline & Childcare by day care centre & Culture & $0.000^{*}$ & 0.05 & 0.02 & 0.15 \\
\hline & Childcare informal & Culture & $0.016^{*}$ & 3.25 & 1.24 & 8.51 \\
\hline \multirow[t]{5}{*}{ Other } & Family affects career & Gender & $0.030^{*}$ & 0.24 & 0.07 & 0.87 \\
\hline & Equal household chores & Culture & $0.002^{*}$ & 0.03 & 0.00 & 0.29 \\
\hline & Household by someone else & Culture & $0.028^{*}$ & 11.77 & 1.30 & 106.40 \\
\hline & Equal care of children & Culture & $0.007^{*}$ & 0.16 & 0.04 & 0.60 \\
\hline & Childcare by day care centre & Culture & $0.000^{*}$ & 0.01 & 0.00 & 0.07 \\
\hline \multirow[t]{7}{*}{ I don't know } & Full-time work preference & Gender & $0.000^{*}$ & 0.40 & 0.25 & 0.63 \\
\hline & Equal opportunities partners & Gender & $0.001^{*}$ & 2.11 & 1.35 & 3.31 \\
\hline & & Culture & $0.000^{*}$ & 0.36 & 0.23 & 0.58 \\
\hline & Career affects family & Gender & $0.007^{*}$ & 1.78 & 1.17 & 2.70 \\
\hline & Partner's career affects family & Gender & 0.523 & 1.21 & 0.67 & 2.19 \\
\hline & & Culture & 0.211 & 1.52 & 0.79 & 2.92 \\
\hline & & Gender ${ }^{*}$ Culture & $0.032^{*}$ & 0.40 & 0.18 & 0.93 \\
\hline
\end{tabular}




\begin{tabular}{|c|c|c|c|c|c|c|}
\hline \multirow{2}{*}{ Specialty } & \multirow{2}{*}{ Outcome $^{\dagger}$} & \multirow{2}{*}{ Predictor $^{* *}$} & \multirow{2}{*}{$\mathrm{p}$} & \multirow{2}{*}{ Odds Ratio } & \multicolumn{2}{|c|}{ 95\% C.I. for Odds Ratio } \\
\hline & & & & & Lower & Upper \\
\hline & Equal household chores & Gender & $0.002^{*}$ & 2.17 & 1.33 & 3.56 \\
\hline & & Culture & $0.000^{*}$ & 0.14 & 0.08 & 0.26 \\
\hline & Household by someone else & Culture & $0.010^{*}$ & 2.21 & 1.21 & 4.05 \\
\hline & Childcare by day care centre & Culture & $0.000^{*}$ & 0.04 & 0.02 & 0.07 \\
\hline
\end{tabular}

†Outcome: working hours (full-time, part-time) and work-life issues (agree, disagree)

**Predictor variables: gender (female, male) and culture (The Netherlands, Sweden)

\section{Discussion}

At the start of medical education, a gender gap in preferences for surgery and paediatrics, as well as full-time work, is present in the Netherlands. The Swedish working culture seems to have a levelling effect on preferences for specialty choice and full-time work. However, in most preferred specialties and regardless of the working culture, female students are less likely to be interested in full-time work than male students. Simultaneously, women more often expect that their careers will influence their future family life and attach more importance to equality in career and family responsibilities.

Our study shows that first year medical students have preferences for specific specialties, and also anticipate particular work-life issues to play a role in their future lives. Both gender and cultural differences are found. In line with previous research, surgery was confirmed to be a more popular specialty preference for male students and paediatrics and gynecology for females. . $^{21,23,24}$ The proportion found in this study of female students preferring certain specialty preferences may mirror the presence of female physicians in these specialties. ${ }^{6,8}$ In this study, many specialty preferences of first year female students relate less often to a full-time work preference than the preferences of male students. It has been reported earlier that female physicians view their specialty choices as an integral part of their family life more often than male physicians. ${ }^{10}$ For instance, our study shows that female students who are interested in family medicine anticipate an influence of family life on their career more than men. Students seem to echo female physicians' struggle in balancing their professional career and family needs. ${ }^{10,25,26}$

When first year students are undecided, this is associated with typical work-life preferences and more specific with the anticipated impact of their partner's career on family life. This may indicate that students remain undecided due to other factors than solely their own interest in a specialty or their own desires for a future division of care tasks. Possibly, students who are decided are more determined to make their wishes come true.

We found that gender differences in specialty and working hour preferences are more pronounced in the Netherlands, where women more often anticipate part-time work in the future. In Sweden, gender equality is facilitated by the government such as by parental leave and day care centres. Swedish female students emphasize equality in careers the most. In the Netherlands, women and men have different Int J Med Educ. 2013;4:214-220 opinions on equality in work-life balance, with especially women opting for part-time work and men considering family responsibilities less often. ${ }^{16,27}$ However, despite these cultural differences, many women in the Netherlands and Sweden desire an option to work part-time.

Female specialists, teachers and mothers may be role models for female medical students in particular. Research has determined that full-time working mothers raise daughters who prefer to work more hours. ${ }^{27}$ In particular, Dutch medical students, who more often have part-time working mothers, may lack female role models showing them how to organize work-life balance or how to practice their preferred specialty. ${ }^{8}$ Male medical students seem to be less involved in equality in career opportunities or expect support from their partners, and wish to work full-time. ${ }^{28}$ Yet, despite more gender equality in Sweden and facilities in childcare, and despite the highly educated and full-time working mothers of Swedish medical students, also in Sweden gender differences remained present in our findings with respect to specialty and full-time working preferences.

\section{Strength and weakness}

In our study, we focused on the "work"-side of the work-life balance as we explored the baseline of medical students' specialty preferences in relation to gender-specific work-life issues. We also compared two different countries with different working cultures. Our study has some limitations. In a cross-sectional study, causal relations cannot be clarified. Next to this, students' career preferences at the beginning of medical education may neither be fixed nor decisive for actual future decisions. In our study population Swedish students are on average four years older when they start medical education. This age difference could have influenced our results, in which Swedish students emphasize equality matters more. However in many specialties women of both countries prefer full-time work to a far lesser degree. And finally, in preparation for logistic regression we categorized those students with more than one specialty preference in the "I don't know" group, which might have affected the outcome. Strength is that our study is conducted in a large sample across several cohorts with a high response rate.

During medical education, individual competences that suit a certain specialty may be further developed by career advising and mentoring. ${ }^{29}$ When first year medical students have a clear idea which specialization is appropriate to them and which preconditions are compatible with their expecta- 
tions for future work-life balance, they can clearly target their goals during their studies. Career ambitions of female physicians may benefit from career support. ${ }^{16}$ Without such support, the perceived and practical inaccessibility of specialties to women may increase or compel women to choose those specialties which they feel can be better combined with family life. Further research may focus on whether changes occur in gender-related preferences during, after, and in relation to medical education.

We recommend influencing possible gender bias during undergraduate medical education by mentoring the careers of female and male students, raising awareness of career prospects and supporting them to reflect on work-life issues. Furthermore, as care-taking is a responsibility shared between partners, partners may also take care to facilitate each other's careers. Therefore, each specialty must assure that both women and men can enter the specialty, including those physicians with larger responsibilities in their private lives.

\section{Conclusion}

When medical students have yet to begin their training, students have gendered specialty- and work-life preferences which relate to each other and which are significantly more pronounced in the Netherlands than in Sweden. For example, female students prefer full-time work less often than male students in most preferred specialties, particularly Dutch female students with a preference for surgery. When female students prefer surgery, they highly emphasize equality in career opportunities, especially in Sweden.

Probably, students' perceptions reflect current genderrelated segregation in specialties and working cultures. However, it is also a signal regarding a workforce-to-be which represents a potential change. Medical education and specialties need to be aware of gendered specialty choice preferences or work-life expectations, taking into account particular aspects of the working culture.

\section{Acknowledgement}

The authors wish to thank Tess Pepping for her work.

\section{Conflict of Interest}

The authors declare that they have no conflict of interest.

\section{References}

1. Boulis A, Jacobs J, Veloski JJ. Gender segregation by specialty during medical school. Acad Med. 2001;76(10 Suppl):S65-S7.

2. Elston MA. Women and medicine: the future. London: Royal College of Physicians, 2009.

3. Kilminster S, Downes J, Gough B, Murdoch-Eaton D, Roberts T. Women in medicine--is there a problem? A literature review of the changing gender composition, structures and occupational cultures in medicine. Med Educ. 2007;41(1):39-49.

4. White FS, McDade S, Yamagata H, Morahan PS. Gender-related differences in the pathway to and characteristics of U.S. Medical school deanships. Acad Med. 2012;87(8):1015-23.

5. AAMC. Women in U.S. Academic Medicine Statistics and Benchmarking Report 2009-2010 [cited 01 March 2011]; Available from: https://
members.aamc.org/eweb/upload/Women\%20in\%20U.S.\%20Academic\%20 Medicine\%20Statistics\%20and\%20Benchmarking\%20Report\%202009-2010. pdf.

6. Capacity institution. Capacity plan 2010 Part I: Medical specialists. Utrecht, January 2011.

7. Lefevre JH, Roupret M, Kerneis S, Karila L. Career choices of medical students: a national survey of 1780 students. Med Educ. 2010;44(6):603-12.

8. Heiligers PJ, Hingstman L. Career preferences and the work-family balance in medicine: gender differences among medical specialists. Soc Sci Med. 2000;50(9):1235-46.

9. Carr PL, Gareis KC, Barnett RC. Characteristics and outcomes for women physicians who work reduced hours. J Womens Health (Larchmt). 2003;12(4):399-405.

10. Buddeberg-Fischer B, Stamm M, Buddeberg C, Bauer G, Haemmig O, Knecht $\mathrm{M}$, et al. The impact of gender and parenthood on physicians' careers--professional and personal situation seven years after graduation. BMC Health Serv Res. 2010;10(40).

11. Goldacre MJ, Laxton L, Lambert TW. Medical graduates' early career choices of specialty and their eventual specialty destinations: UK prospective cohort studies. BMJ. 2010;341:c3199:c3199.

12. Van der Reis L. Causes and effects of a changed gender ratio in medicine. Med Teach. 2004;26(6):506-9.

13. Statistics Sweden. Women and men in Sweden 2010 facts and figures. Stockholm Hela publikationen; 2010.

14. Bertakis KD. The influence of gender on the doctor-patient interaction. Patient Educ Couns. 2009;76(3):356-60.

15. Jagsi R, DeCastro R, Griffith KA, Rangarajan S, Churchill C, Stewart A, et al. Similarities and differences in the career trajectories of male and female career development award recipients. Acad Med. 2011;86(11):141521 .

16. Pas B, Peters P, Eisinga R, Doorewaard H, Lagro-Janssen A. Explaining career motivation among female doctors in the Netherlands: the effects of children, views on motherhood and work-home cultures. Work Employ Soc. 2011;25(3):487-505.

17. Kusurkar RA, Ten Cate TJ, van Asperen M, Croiset G. Motivation as an independent and a dependent variable in medical education: a review of the literature. Med Teach. 2011;33(5):e242-62.

18. Dehn PB, E. Who's choosing whom? A sociological study of the specialty choices in a Danish context. IJME. 2011(2):36-43.

19. Sanfey HA, Saalwachter-Schulman AR, Nyhof-Young JM, Eidelson B, Mann BD. Influences on medical student career choice: gender or generation? Arch Surg. 2006;141(11):1086-94.

20. Visser J. The first part-time economy in the world: a model to be followed? J Eur Soc Policy. 2002;12(23-42).

21. Compton MT, Frank E, Elon L, Carrera J. Changes in U.S. medical students' specialty interests over the course of medical school. J Gen Intern Med. 2008;23(7):1095-100.

22. Eisenbrey R, Heron A, Gornick JC. The work-family balance: an analysis of European, Japanese, and U.S. work-time policies. Institute Economic Policy, May 23, 2007 [cited 23 Oct 2013]; Available from: http://www. epi.org/publication/bp189/.

23. Fysh TH, Thomas G, Ellis H. Who wants to be a surgeon? A study of 300 first year medical students. BMC Med Educ. 2007;19;7:2.:2.

24. Soethout MB, Heymans MW, Cate OT. Career preference and medical students' biographical characteristics and academic achievement. Med Teach. 2008;30(1):15-22.

25. Askari S, Liss M, Erchull M, Staebel S, Axelson S. Men want equality, but women don't expect it: young adult's expectations for participation in household and child care chores. Psychol Women Quart. 2010;34:243-52.

26. Kreimer M. Labour market segregation and the gender-based division of labour. Eur J Wom Stud. 2004; 11(2):223-246.

27. Putten van AE, Dykstra PA, Schippers JJ. Just like mom? The intergenerational reproduction of women's paid work. Eur Sociol Rev. 2008; 24(4):435-49.

28. Riska E. Gender and medical careers. Maturitas. 2011;68(3):264-7.

29. Frei E, Stamm M, Buddeberg-Fischer B. Mentoring programs for medical students--a review of the PubMed literature 2000-2008. BMC Med Educ. 2010;10:32. 